Check for updates

The BMJ

fgodlee@bmj.com Follow Fiona on Twitter @fgodlee

Cite this as: $B M J 2021 ; 375: \mathrm{n} 2559$

http://dx.doi.org/10.1136/bmj.n2559

Published: 21 October 2021

\title{
Why healthcare needs rebels
}

\section{Fiona Godlee editor in chief}

Members of the Independent Scientific and Advisory Group for Emergencies may be surprised to find themselves portrayed as rebel scientists (doi:10.1136/bmj.n2504), ${ }^{1}$ and critics may see this as yet another reason to distrust or dismiss this self-appointed group. But rebels they have been, and we need rebels if things are to change. Opinions differ as to whether iSAGE has made a positive difference in the UK's response to the covid-19 pandemic, but it has definitely achieved one thing. Through its frequent and open engagement with the public, and by always showing its workings, it has forced the government's advisers to be more transparent and accountable (doi:10.1136/bmj.n2452), ${ }^{2}$ and this has changed the nature and raised the quality of the debate.

Rebels are needed elsewhere across healthcare, to spot what's wrong and champion what's right, and to push for greater openness, constructive discussion, and evidence based change. From its inception the UK National Institute for Health and Care Excellence represented rebellion, establishing evidence based decisions for rationing healthcare, challenging the marketing might of the drug industry and opening up decision making to patients and the public (doi:10.1136/bmj.318.7187.823). ${ }^{3}$ NICE faces ever greater challenges and needs our continuing support (doi:10.1136/bmj.n1093). ${ }^{4}$ But to deserve that support it has to keep close to its radical roots. Relying on a surrogate outcome for its approval of the new cholesterol lowering drug inclisiran, and hiding its cost analysis, are worrying signs that it has lost its rebellious heart (doi:10.1136/bmj.n2462). ${ }^{5}$ These things are not right and must be challenged.

Whether the UK's general practitioners have the stomach for rebellion is something we may soon find out. Under huge and growing pressure (doi:10.1136/bmj.n2517), ${ }^{6}$ and attacks from some sections of the media (doi:10.1136/bmj.n2532), 7 they might reasonably have hoped for the government's recognition and support. Instead the health and social care secretary for England, Sajid Javid, failed to turn up to speak to GPs' representatives

(doi:10.1136/bmj.n2538), ${ }^{8}$ and, rather than engaging constructively, has committed the NHS's limited funds to driving up face-to-face consultations, through a set of non-evidence based, top-down interventions (doi:10.1136/bmj.n2564) that are only likely to make things worse

(https://blogs.bmj.com/bmj/2021/10/15/martin-marshall-we-need-long-term-realistic-and-tangible-solutions-to-solve-the-crisis-in-general-practice). ${ }^{9} 10$

The UK has a hard winter ahead (doi:10.1136/bmj.n2534), ${ }^{11}$ with western Europe's highest rate of covid infection, a vast backlog of untreated illness (doi:10.1136/bmj.n2566), ${ }^{12}$ and the possibility of a serious flu epidemic (doi:10.1136/bmj.n2514). ${ }^{13}$ Now is the time for the government to work with our exhausted health professionals and seek real solutions to the current crisis (doi:10.1136/bmj.n2533). ${ }^{14}$

1 Clarke L. Covid-19's rebel scientists: has iSAGE been a success?BMJ 2021;375:n2504doi: 10.1136/bmj.n2504

2 Mahase E. Covid-19: Vaccine advisory committee must be more transparent about decisions, say researchers. BMJ 2021;375:n2452. doi: 10.1136/bmj.n2452 pmid: 34620583

3 Smith R. NICE: a panacea for the NHS?BM/1999;318:823-4 doi: 10.1136/bmj.318.7187.823 pmid: 10092239

4 Gill D, Baker EH, Hitchings AW. We need clinical guidelines fit for a pandemic. BMJ2021;373:n1093. doi: 10.1136/bmj.n1093 pmid: 33926903

5 Byrne P, Demasi M, Smith SM. NICE guidance on inclisiran should be reconsidered. BM/2021;375:n2462. doi: 10.1136/bmj.n2462 pmid: 34642203

6 lacobucci G. Government's “rescue package" will prompt more GPs to quit, leaders warn. BM/2021;375:n2517. doi: 10.1136/bmj.n2517 pmid: 34649870

7 Oliver D. David Oliver: Daily Mail's campaign on general practice won't help GPs or their patients. BMJ2021;375:n2532doi: 10.1136/bmj.n2532.

8 Salisbury H. Helen Salisbury: Sajid Javid's missed opportunity. BMJ 2021;375:n2538doi: 10.1136/bmj.n2538.

9 Mahase E. GPs overwhelmingly reject health secretary's "rescue plan" for general practice. BMJ2021;375:n2564doi: 10.1136/bmj.n2564.

10 Marshall M. We need long-term, realistic, and tangible solutions to solve the crisis in general practice. BMJ Opinion. Oct 2021. https://blogs.bmi.com/bmi/2021/10/15/martin-marshall-we-need-long-termrealistic-and-tangible-solutions-to-solve-the-crisis-in-general-practice.

11 Mahase E. Winter will be "exceptionally difficult" for NHS irrespective of covid, Chris Whitty warns. BMJ2021;375:n2534doi: 10.1136/bmj.n2534.

12 lacobucci G. Covid-19: Government must reintroduce precautionary measures now, say health leaders. BMJ 2021;375:n2566doi: 10.1136/bmi.n2566.

13 lacobucci G. Covid and flu: what do the numbers tell us about morbidity and deaths?BM/2021;375:n2514. doi: 10.1136/bmi.n2514 pmid: 34649887

14 Sheather J, Slattery D. The great resignation-how do we support and retain staff already stretched to their limit?BMJ 2021;375:n2533doi: 10.1136/bmj.n2533. 